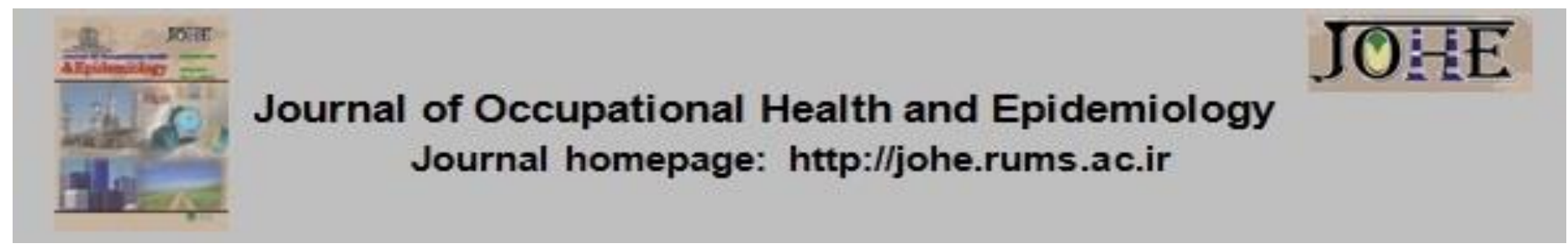

\title{
Assessing Health Anxiety among Healthcare Providers of COVID-19 Patients from March to May 2020, Rafsanjan County, Iran
}

\author{
Mohammadreza Mirzabeigi ${ }^{1}$, Parvin Agha Mohammad Hasani ${ }^{*}$, Ahmadreza Sayadi², Mohammad \\ Safarian ${ }^{3}$, Sobhan Parand Afshar ${ }^{4}$ \\ 1. Assistant Prof, Dept. of Psychiatry, Clinical Research Development Unit (CRDU), Moradi Hospital (Moradi Education and Clinical \\ Centre), Rafsanjan University of Medical Sciences, Rafsanjan, Iran. \\ 2. Assistant Prof, Dept. of Psychiatric Nursing, School of Nursing and Midwifery, Social Determinants of Health Research Center, \\ Rafsanjan University of Medical Sciences, Rafsanjan, Iran. \\ 3. Assistant Prof, Dept. of Internal Medicine, Rafsanjan University of Medical Sciences, Rafsanjan, Iran. \\ 4. Medical Student, Rafsanjan University of Medical Sciences, Rafsanjan, Iran.
}

\section{Article Info}

* Corresponding author:

Parvin Agha Mohammad Hasani,

E-mail:

dr.hadani@rums.ac.ir

\section{Article history}

Received: Jan 2021

Accepted: Mar 2021

\subsection{2/johe.10.1.24}

Print ISSN: 2251-8096 Online ISSN: 2252-0902

Peer review under responsibility of Journal of Occupational Health and Epidemiology
Citation: Mirzabeigi M, Agha Mohammad Hasani P, Sayadi A, Safarian M, Parand Afshar S. Assessing Health Anxiety among Healthcare Providers of COVID-19 Patients from March to May 2020, Rafsanjan County, Iran. JOHE 2021; 10(1):24-30.

\section{Introduction}

Despite remarkable advances made in medicine to prevent and treat contagious diseases, infectious diseases with epidemic and pandemic potentials still remain a health problem worldwide [1]. Coronavirus Disease 2019 (COVID-19), caused by a coronavirus, is one of these diseases, which was unknown before its outbreak in Wuhan (China) in December 2019. COVID-19 is a rapidly transmissible pathogenic viral infection. Coronaviruses are a large group of viruses that infect both animals and humans and cause respiratory diseases, ranging from a mild cold to severe pneumonia. In rare cases, animal coronaviruses infect humans and spread among them in the aftermath. Severe acute respiratory syndrome (SARS) is also caused by a coronavirus that can be transmitted from animals to humans [2]. Middle East Respiratory Syndrome (MERS) is 
the most recent viral respiratory disease caused by a novel coronavirus, which was first identified in the Middle East in 2012. Scientists believe that MERS was transmitted by camels to humans [3]. Fever, dry cough, and fatigue are the most common symptoms of COVID-19. About one out of six people getting infected with COVID-19 becomes seriously ill and develops breathing difficulties. The mortality rate of this disease is almost $2 \%$. Some countries have so far developed vaccines against COVID-19. However, antibiotics cannot be used to treat this viral infection [2-4]. Professions and occupations play a decisive role in the mental health of people. Nursing creates a lot of job stress in nurses who constantly face stressful factors at work [5]. The National Institute for Occupational Safety and Health (NIOSH) in the United States has declared that nursing, among the 130 studied jobs, has a high place in terms of doctor visits for physical and mental health problems [6]. Therefore, nurses are at a high risk of mental and physical diseases and negative jobrelated stress due to the sensitivity of their occupational responsibilities and continuous interactions with patients [7]. Nurses experience high levels of anxiety due to stressful situations at work [8]. Accordingly, nurses employed in intensive care units (ICUs) [5], infectious diseases wards [9], emergency wards [10], psychiatric wards [11], and the wards for special patients may be under high levels of workplace stress. Stressors in the ICUs include contacts with patients and their companions, heavy workloads, the necessity of the prompt response by nurses to emergency situations, continuous contacts with emergency patients, heavy responsibility for dealing with ICU patients, and witnessing patient death [12].

Anxiety disorders affect mental health, being the most prevalent psychiatric disorders at present [13]. Health anxiety is defined as a broad spectrum of worries that people may have about their health. It is a severe cognitive disorder characterized by misinterpretation of symptoms and bodily changes resulting from the individual's beliefs regarding health or illness [14]. Health anxiety is a continuum ranging from mild worries about physical sensations to intense fears of severe illnesses and preoccupations with bodily sensations. These worries are often reinforced by emotional mental images, making patients experience severe health anxiety. Individuals experiencing severe health anxiety meet diagnostic criteria of the health anxiety disorder based on the Diagnostic and Statistical Manual of Mental Disorders (DSM-5) [15].

Research shows that health anxiety leads to disabilities and huge costs for the nursing community [16]. Workplace stress and personality traits of healthcare personnel make them more vulnerable to health anxiety. Therefore, effective interventions are required to reduce stressors in their workplace. Support systems are necessary at hospitals for providing suitable medical care services as well as promoting health and efficiency of the society of nurses, given the impact of health anxiety on physical and mental aspects of nurses, its effect on health care services provided by them, and the difference observed in the level of the services in different wards [17]. Against this background, this study aims to assess health anxiety in the treatment team dealing with COVID19 patients.

\section{Materials and Methods}

The statistical population of this descriptive study consisted of $101 \mathrm{HCWs}$ who witnessed death due to COVID-19 at Ali ibn-Abi Talib Hospital in Rafsanjan County (the only hospital assigned to COVID-19 patients in this county) from March to May 2020. All of the personnel were enrolled in this study using the census sampling method. Besides, this study received the ethics code of IR.RUMS.REC.1399.058 from the Ethics Committee of Rafsanjan University of Medical Sciences.

The inclusion criteria were having at least six months of work experience, holding a high school diploma or higher degrees, being employed as a service staff member $(n=16)$, being a nurse $(n=$ $66)$, being a radiology staff member $(n=7)$, being a laboratory staff member $(n=12)$, having no history of known mental illnesses, not undergoing current treatments for disorders, such as treatmentresistant depression, having no history of chronic and difficult physical diseases to cure, including multiple sclerosis, and not grieving the death of a close relative in the past three months.

The exclusion criterion was failure to complete the checklist and the Short Health Anxiety Inventory (SHAI).

Adequate explanations were given to the participants. Besides, they were taught how to complete the online inventory and the checklist, with informed consent forms received from them.

The research tools included the demographic checklist and the SHAI.

The demographic checklist included characteristics, such as age, gender, work experience, education level, and type of profession of the personnel.

The full and original form of the SHAl was developed by Salkovskis and Warwick (1989) based on the cognitive model of health anxiety and 
hypochondria [18]. The short form of the HSAI, developed by the same researchers (2002), consisted of 18 items [19]. This scale specifically measures worries and anxieties about health status. The questionnaire includes the three main factors of general health, concerns, and negative consequences. Besides, each item has 4 options, with each option including a description of the individual components of health and the illness in the form of a news statement the subject would choose among the sentences that best described them. Options (a) and (d) received 0 and 3 points, respectively. The total scores ranged from 0 to 54 . Score 18 or higher indicated suffering and anxiety, and score 37 or higher indicated the health anxiety disorder [18]. The inventory had an overall score (overall health concern) with two subscales of illness likelihood and negative outcomes of illness development. Besides, the Cronbach's alpha of 0.89 was calculated by Salkovskis et al (2002) for the HSAl [18]. Nargesi et al validated this questionnaire in Iran. The results suggested that the HSAl was adequate for detecting health anxiety among Iranian students, and the Cronbach's alpha of 0.75 was calculated for its Iranian version. The construct validity of this questionnaire was reported to be satisfactory [20]. Besides, online versions of the inventory and the checklist were prepared, and the links were sent to the participants as attachments. In addition, the participants were asked to fill out the checklist and the HSAl whenever they were free, not preoccupied, and assured of data confidentiality. The data were analyzed using an ANOVA and the independent t-test in SPSS $v 18$, and the significance level was set at $\mathrm{P}<0.05$.

\section{Results}

A total of 101 healthcare staff dealing with COVID19 patients participated in this study. The mean age of the participants was $33.74 \pm 8.33$ years (ranging from 23 to 47 years), and the average work experience was $10.28 \pm 7.29$ years (ranging from 1 to 24 years). Out of the 101 personnel, 46 $(45.5 \%)$ were male, and 55 (54.5\%) were female. Besides, out of the 101 personnel, $72.3 \%$ suffered from mild anxiety, $24.7 \%$ from moderate anxiety, and $3 \%$ from health anxiety. The mean score of health anxiety for the participants less than 35 years old was higher than that for those older than 35 years, but the difference was not significant $(p=$ 0.052 ). The mean score of health anxiety for the males $(p=0.04)$ and for those witnessing death of COVID-19 patients $(p=0.036)$ was higher than that for others. In addition, a significant difference was observed in the mean score of health anxiety in terms of work experience $(p=0.037)$, workplace $(p=0.001)$, and occupation $(p<0.001)($ Table 1$)$.

Table 1. The mean score of health anxiety in the Health Care Providers of COVID-19 Patients from March to May 2020, Rafsanjan County $(n=101)$

\begin{tabular}{|c|c|c|c|c|}
\hline \multicolumn{2}{|c|}{ Variable } & No (\%) & Mean \pm SD & P-value \\
\hline \multirow{2}{*}{ Gender } & Male & $46(45.5)$ & $14.65 \pm 10.21$ & \multirow{2}{*}{$0.04^{* a}$} \\
\hline & Female & $55(54.5)$ & $11.02 \pm 6.47$ & \\
\hline \multirow{3}{*}{ Education } & High school diploma & $14(13.9)$ & $10.14 \pm 6.15$ & \multirow{3}{*}{$0.288^{b}$} \\
\hline & Up to a bachelor's & $72(71.3)$ & $13.51 \pm 9.21$ & \\
\hline & Higher than a bachelor's & $15(14.8)$ & $11.00 \pm 6.48$ & \\
\hline \multirow{2}{*}{ Marital status } & Married & $66(65.3)$ & $12.34 \pm 8.39$ & \multirow{2}{*}{$0.602^{a}$} \\
\hline & Single & $35(34.7)$ & $13.28 \pm 8.89$ & \\
\hline \multirow{2}{*}{$\begin{array}{c}\text { Witnessing the } \\
\text { death of a patient }\end{array}$} & Yes & $39(38.6)$ & $15.15 \pm 10.55$ & \multirow{2}{*}{$0.036^{a}$} \\
\hline & No & $62(61.4)$ & $11.11 \pm 6.60$ & \\
\hline \multirow{2}{*}{ Age (year) } & Up to 35 & $63(62.4)$ & $13.95 \pm 9.16$ & \multirow{2}{*}{$0.052^{a}$} \\
\hline & More than 35 & $38(37.6)$ & $10.55 \pm 6.98$ & \\
\hline \multirow{3}{*}{$\begin{array}{c}\text { Work experience } \\
\text { (year) }\end{array}$} & $<10$ & $55(54.5)$ & $14.72 \pm 9.59$ & \multirow{3}{*}{$0.032^{* b}$} \\
\hline & $11-20$ & $36(35.6)$ & $10.14 \pm 6.07$ & \\
\hline & $>21$ & $10(9.9)$ & $11.30 \pm 8.21$ & \\
\hline \multirow{4}{*}{ Workplace } & COVID & $44(43.6)$ & $15.18 \pm 5.53$ & \multirow{4}{*}{$0.001^{* b}$} \\
\hline & ICU & $38(37.6)$ & $12.31 \pm 11.31$ & \\
\hline & Radiology & $7(6.9)$ & $13.00 \pm 2.0$ & \\
\hline & Laboratory & $12(11.9)$ & $4.42 \pm 3.12$ & \\
\hline \multirow{4}{*}{ Occupation } & Nurse & $66(65.3)$ & $14.85 \pm 9.06$ & \multirow{4}{*}{$<0.001^{* b}$} \\
\hline & Radiology staff & $7(6.9)$ & $4.42 \pm 3.12$ & \\
\hline & Laboratory staff & $12(11.9)$ & $13.00 \pm 2.00$ & \\
\hline & Services staff & $16(15.9)$ & $9.75 \pm 6.00$ & \\
\hline
\end{tabular}

a: Independent t-test, b: ANOVA, * P-value $\leq 0.05$ 
The results of the post hoc test showed that the mean score of health anxiety of the participants with 10 years of work experience was higher than that of those with 11 to 20 years of work experience $(p=0.033)$. In addition, the mean score of health anxiety of those working in the COVID-19 ward $(p<0.001)$ and in the ICU $(P=0.018)$ was higher than that of those working in the laboratory (Table 2). However, the difference in other cases was not significant.

Table 2. Results of the Tukey post hoc test on comparing multiple differences in the mean health anxiety score based on work experience, workplace, and Occupation

\begin{tabular}{ccccc}
\hline Variable & \multicolumn{2}{c}{ Groups } & Mean Difference & P-value \\
\hline $\begin{array}{c}\text { Work experience } \\
\text { (year) }\end{array}$ & Up to 10 & $11-20$ & 4.583 & $0.033^{*}$ \\
\hline Workplace & COVID & Laboratory & 10.76 & $<0.001^{*}$ \\
\cline { 2 - 5 } & ICU & Laboratory technician & 10.40 & $0.018^{*}$ \\
\hline Occupation & Nurse & Lann & $<0.001^{*}$ \\
\hline
\end{tabular}

${ }^{*} \mathrm{P}$-value $\leq 0.05$; the difference in other cases was not significant.

\section{Discussion}

This study aimed to assess health anxiety in the treatment team of COVID-19 patients during the first trimester of 2020. For this purpose, 101 personnel of the Ali ibn-Abi Taleb Hospital in Rafsanjan County, who dealt with COVID-19 patients, were assessed. The results showed that $3 \%$ of them suffered from health anxiety, and $97 \%$ experienced mild to moderate anxiety. The mean score of health anxiety for the personnel was 12.67 \pm 8.53 . Hosseini et al calculated the mean score of health anxiety at 38.40 for nurses [8]. Similarly, Abdi et al reported that the mean score of health anxiety was 30.08 for nurses working in the general medicine ward and 44.45 for those working in the ICU [17]. Karimi et al obtained the mean score of 17.56 for health anxiety in students [21]. Babaei et al assessed the dimensions of health anxiety in nurses working at medical centers of Tehran and showed that they experienced more negative emotions than ordinary people; however, no significant difference was found between them in terms of positive emotions [16]. Sarboozi et al reported moderate levels of depression, stress, and anxiety in nurses during the COVID-19 pandemic at a hospital in the Torbat-e Heydariyeh County [22]. Mental health of Chinese nurses was assessed in a study during the COVID-19 pandemic in 2020. Accordingly, the nurses experienced symptoms, such as irritability, unwillingness to rest, and psychosis. However, they refused to receive psychological services and stated that they had no problems. Their main psychological problems during the pandemic were concerns over getting infected with the disease, fears of transmitting the infection to family members, unwillingness to be quarantined in the hospital, worries about shortage of personal protective equipment (PPE), and the feeling that COVID-19 patients were managed inefficiently.
Many nurses believed that they did not need psychological interventions, but they needed enough rest and PPE. They expressed the need for sufficient trainings in psychological skills for coping with anxiety, panic, and other emotional problems [23]. Chen et al (2019) showed that employment in a specialized hospital, female gender, married life, low income, introversion, high levels of education, and physical illnesses were risk factors for health anxiety [24]. Fear and anxiety resulting from probable infection with COVID-19 are destructive and can cause psychological abnormalities and stress. Fear and stress stimulate the hypothalamus after the increased secretion of cortisol by the adrenal cortex and short-term stimulation of sympathetic nerves to cope with stressors [25]. However, longterm fear and stress as well as the body's response to them, which elevate the cortisol level and stimulate the sympathetic nervous system, have destructive impacts. Besides, they weaken the immune system, thereby reducing the body's ability to fight diseases, including COVID-19 and others [26]. Therefore, coping with stress makes the community resistant to diseases [27]. Yazdanpanah et al reported that the stress resulting from the spread of COVID-19 could cause marital boredom and premenstrual syndrome in female nurses [28]. Sabet et al showed that managing stress at hospitals during the COVID-19 crisis and teaching communication skills could help improve performance and efficiency of the entire healthcare workers, especially nurses, thereby influencing their organizational commitment [29]. The results of previous studies during the SARS and Ebola outbreaks showed high prevalence of psychological disorders in the form of high levels of anxiety, stress, and depression [30]. The study by Lai et al on hospital doctors and nurses, in Wuhan 
during the spread of COVID-19, showed that medical care workers experienced high levels of depressive symptoms (12.1\%) and anxiety (11.6\%) [31]. The results of the present study are consistent with those of the study by Koh et al who reported the presence of stress (16\%) in over half of nurses during the SARS epidemic in Singapore [32]. Besides, nurses in direct contact with SARS patients experienced higher levels of anxiety in another study in Hong Kong during the SARS epidemic [33]. These results were consistent with those of the present research as well. Wu et al assessed mental health in medical staff fighting the SARS outbreak in 2009 and reported a high level of stress in $42 \%$ of them [34]. In contrast, $25 \%$ of the healthcare employees suffered from anxiety, and $3 \%$ experienced health anxiety in the present study. Nouroozi et al studied the general health and magnitude of emotional responses in nurses working in ICUs of two hospitals in Baqiyatallah University of Medical Sciences. Accordingly, they reported $33,33.9$, and $30.8 \%$ of stress, anxiety, and depression, respectively, in the mentioned nurses [35]. Nurses working in COVID-19 wards are prone to psychological disorders due to the nature of their profession, heavy protective clothing, N95 respirators, as well as the risk of getting infected with COVID-19 and transmitting it to others.

No significant relationship was found between age and anxiety in the present study, having been inconsistent with the results of the research by Khamseh et al [36]. Early theories of psychologists and psychiatrists claimed that increased prevalence of psychological symptoms in acute and stressful situations would be limited in those with a history of psychological illnesses and disorders. Recent research shows that people with no history of mental disorders may experience psychological symptoms and disorders in acute stressful situations, such as epidemics, including the COVID-19 pandemic. The association between infectious epidemics and health anxiety has been discussed by researchers since the beginning of the influenza epidemic in 2009 [37]. According to the results of a study on epidemics in recent years, anxiety increased in urban areas during epidemics. For example, during the SARS outbreak in Hong Kong and Canada, the level of anxiety increased substantially following an increase in the probability of infection with this disease [38]. One of the limitations of this study was the completing of a number of questionnaires by nurses during their work activities, which could have affected accuracy of the results. Therefore, caution should be exercised in generalizing the results. It is recommended that employee health anxiety be monitored periodically during the COVID-19 outbreak crisis. Besides, it is suggested that the effectiveness of psychological stress management interventions be investigated.

\section{Conclusion}

The results of this study showed that almost a quarter of the nurses dealing with COVID-19 patients suffered from moderate to severe health anxiety. Many healthcare workers of COVID-9 patients suffered from a high level of anxiety. This anxiety was more common in men and the staff with less work experience. The study of mental health is critically important during the COVID-19 crisis. Accordingly, any delay in the treatment of mental disorders could produce undesirable outcomes. Therefore, more research must be conducted on mental health of treatment teams dealing with COVID-19 patients. Accordingly, it is recommended that health anxiety be compared in different waves of the COVID-19 epidemic among nurses. Besides, it is suggested that risk factors for health anxiety be examined, and the effects of psychological therapies on reducing health anxiety be investigated among nurses.

\section{Acknowledgement}

We would like to extend our gratitude to the staff of the Ali ibn-Abi Talib Hospital, who participated in this study despite their heavy workloads. Besides, we would like to appreciate the vice chancellor for Research and Technology at Rafsanjan University of Medical Sciences for his support of this research project.

Conflict of interest: None declared.

\section{References}

1. Balkhair AA. COVID-19 Pandemic: A New Chapter in the History of Infectious Diseases. Oman Med J 2020; 35(2):e123.

2. Fehr AR, Perlman S. Coronaviruses: an overview of their replication and pathogenesis. Methods Mol Biol 2015; 1282:1-23.

3. Hui DS, Memish ZA, Zumla A. Severe acute respiratory syndrome vs. the Middle East respiratory syndrome. Curr Opin Pulm Med 2014; 20(3):233-41.

4. Yang N, Shen HM. Targeting the Endocytic Pathway and Autophagy Process as a Novel Therapeutic Strategy in COVID-19. Int J Biol Sci 2020; 16(10):1724-31.

5. Charkhat Gorgich EA, Zare S, Ghoreishinia G, Barfroshan S, Arbabisarjou A, Yoosefian N. Job Stress and Mental Health among Nursing Staff 
of Educational Hospitals in South East Iran. Thrita 2017; 6(1):e45421.

6. Wachs JE. The American Association of Occupational Health Nurses: Seventy-Five Years of Education, Practice, and Research. Workplace Health Saf 2017; 65(4):148-53.

7. Barton A. Patient Safety and Quality: An Evidence-Based Handbook for Nurses. AORN J 2009; 90(4):601-2.

8. Salimi Bajestani H, Hosseini Ghomi T, Zakeri N. Relationship Religious Orientation and Hope with Health Anxiety among Women Nurses in Imam Khomeini Hospital of Tehran. Iranian Journal of Nursing Research 2014; 9(1):17-24.

9. Torshizi L, Ahmadi F. Job Stressors from Clinical Nurses' Perspective. Iran Journal of Nursing 2011; 24(70):49-60.

10. Shareinia $H$, Khuniki F, Bloochi Beydokhti $T$, Eydi Zeynabad A, Hosseini M. Comparison between job stress among emergency department nurses with nurses of other departments. Quarterly Journal of Nersing Management 2018; 6(3):48-56.

11. Ghanizade A, Shaker Dioulagh A. Comparison Tolerance and Perceived Stress among Nurses in the Psychiatric Ward and Special Care Unit. Iranian Journal of Nursing Research 2018; 13(4):32-8.

12. Najimi A, Goudarzi AM, Sharifirad G. Causes of job stress in nurses: A cross-sectional study. Iran J Nurs Midwifery Res 2012; 17(4):301-5.

13. Sadock BJ, Sadock VA, Ruiz P. Kaplan and Sadock's Synopsis of Psychiatry: Behavioral Sciences/Clinical Psychiatry. 11th ed. Philadelphia, United States: Lippincott Williams \& Wilkins; 2014

14. Asmundson GJG, Fergus TA. Chapter One The Concept of Health Anxiety. In: HedmanLagerlöf E, editor. The Clinician's Guide to Treating Health Anxiety: Diagnosis, Mechanisms, and Effective Treatment. $1^{\text {st }}$ ed, Cambridge, Massachusetts, United States: Academic Press; 2019. P.1-18.

15. Kobori O, Okita M, Shiraishi T, Hasegawa $T$, lyo $M$. Health anxiety and healthcare costs in Japanese individuals: an Internet survey. Health Psychol Behav Med 2014; 2(1):833-40.

16. Babaei Nadinlue K, Amiry S, Farzalizade V, Sattari M. Investigate the Dimensions of Health Anxiety in Nurses Compared to Normal People based on the Role of Maladaptive Personality Dimensions [Pid-5]. Journal of Nurse and Physician within War 2018; 6(20):28-35.

17. Abdi $H$, Eissazadegan A, Michaeli Manee F. Comparison of Health Anxiety, Sensory Processing Sensitivity and Harm Avoidance among Nurses of Critical and Public Care Unit. Rooyesh-e-Ravanshenasi Journal 2018; 7(7):189-206.

18. Salkovskis PM, Rimes KA, Warwick HMC, Clark DM. The Health Anxiety Inventory: development and validation of scales for the measurement of health anxiety and hypochondriasis. Psychol Med 2002; 32(5):843-53.

19. Alberts NM, Hadjistavropoulos HD, Jones SL, Sharpe D. The Short Health Anxiety Inventory: a systematic review and meta-analysis. J Aanxiety Disord 2013; 27(1):68-78.

20. Nargesi F, Izadi F, Kariminejad K, Rezaii Sharif A. The investigation of the reliability and validity of Persian version of Health anxiety questionnaire in students of Lorestan University of Medical Sciences. Educational Measurement 2017; 7(27):147-60.

21. Karimi J, Homayouni A, Homayouni F. The Prediction of Health Anxiety based on Experiential Avoidance and Anxiety Sensitivity among non-clinical Population. Journal of Research in Psychological Health 2019; 12(4):66-79.

22. Sarboozi Hosein Abadi T, Askari M, Miri K, Namazi Nia M. Depression, stress and anxiety of nurses in COVID-19 pandemic in Nohe-Dey Hospital in Torbat-e-Heydariyeh city, Iran. Journal of Military Medicine 2020; 22(6):526-33.

23. Kang L, Li Y, Hu S, Chen M, Yang C, Yang BX, et al. The mental health of medical workers in Wuhan, China dealing with the 2019 novel coronavirus. Lancet Psychiatry 2020; 7(3):e14.

24. Chen Q, Zhang Y, Zhuang D, Mao X, Mi G, Wang $D$, et al. Health anxiety in medical employees: A multicentre study. J Int Med Res 2019; 47(10):4854-61.

25. Barrett K, Barman S, Yuan J, Brooks H. Ganong's Review of Medical Physiology. $26^{\text {th }}$ ed, New York, United States: McGraw-Hill Education; 2019.

26. Yaribeygi $H$, Panahi $Y$, Sahraei $H$, Johnston TP, Sahebkar A. The impact of stress on body function: A review. EXCLI J 2017; 16:1057-72.

27. Allahtavakoli M. Coping with stress of COVID_19 epidemic. Journal of Jiroft University of Medical Sciences 2020; 7(1):253-4.

28. Yazdanpanah T, Ghavi Panjeh M. The effect of stress due to coronavirus outbreak on premenstrual syndrome and marital boredom of female nurses of Amir Almonin Hospital. Paper presented at: The Second Congress of New Findings in Family, Mental Health, Disorders, Prevention and Education; 2020 Jun 13; Adiban Institute of Higher Education, Adiban University, Tehran, Iran.

29. Sabet A, Jabari O, Alipour S, Sabet MR. Investigating the relationship between stress management and organizational commitment among nurses during Covid-19 pandemic, with the mediating role of communication skills training. Journal of Modern Medical Information Sciences 2020; 6(2):1-10.

30. Li L, Wan C, Ding R, Liu Y, Chen J, Wu Z, et al. Mental distress among Liberian medical staff working at the China Ebola Treatment Unit: a cross sectional study. Health Qual Life Outcomes 2015; 13:156. 
31. Lai J, Ma S, Wang Y, Cai Z, Hu J, Wei N, et al. Factors Associated With Mental Health Outcomes Among Health Care Workers Exposed to Coronavirus Disease 2019. JAMA Netw Open 2020; 3(3):e203976.

32. Koh D, Lim MK, Chia SE, Ko SM, Qian F, Ng V, et al. Risk perception and impact of Severe Acute Respiratory Syndrome (SARS) on work and personal lives of healthcare workers in Singapore: what can we learn? Med Care 2005; 43(7):676-82.

33. Poon E, Liu KS, Cheong DL, Lee CK, Yam LY, Tang WN. Impact of severe respiratory syndrome on anxiety levels of front-line health care workers. Hong Kong Med J 2004; 10(5):325-30.

34. Wu P, Fang Y, Guan Z, Fan B, Kong J, Yao Z, et al. The psychological impact of the SARS epidemic on hospital employees in China: exposure, risk perception, and altruistic acceptance of risk. Can J Psychiatry 2009; 54(5):302-11.
35. Nouroozi Kushali A, Hajiamini Z, Ebadi A, Khamseh F, Rafieyan Z, Sadeghi A. Comparison of Intensive Care Unit and General Wards Nurses' Emotional Reactions and Health Status. Advances in Nursing \& Midwifery 2014; 23(80):15-23.

36. Khamseh F, Roohi H, Ebaady A, Hajiamini Z, Salimi H, Radfar S. Survey Relationship between demographic factors and stress, anxiety and depression in nurses working in selected hospitals in Tehran city. Journal of Holistic Nursing and Midwifery 2011; 21(1):1321.

37. Wheaton MG, Abramowitz JS, Berman NC, Fabricant LE, Olatunji BO. Psychological Predictors of Anxiety in Response to the H1N1 (Swine Flu) Pandemic. Cognit Ther Res 2012; 36(3):210-8.

38. Cheng C, Cheung MW. Psychological responses to outbreak of severe acute respiratory syndrome: a prospective, multiple time-point study. J Pers 2005; 73(1):261-85. 